\title{
Is hyperlipidemia a potential protective factor against intraoperative awareness in cardiac surgery?
}

\author{
Qingshui Zheng ${ }^{1}$, Qian Wang ${ }^{2}$, Chaoqun $\mathrm{Wu}^{3}$, Zhifa Wang ${ }^{2^{*}}$ and Hushan $\mathrm{Ao}^{3^{*}}$
}

\begin{abstract}
Background: Intraoperative awareness is a dreaded complication that leads to psychological sequelae such as posttraumatic stress disorder, especially in patients undergoing cardiac surgery. This study investigated the incidence of awareness among patients receiving cardiac surgery and sought to identify the risk factors contributing to intraoperative awareness.
\end{abstract}

Methods: Patients with informed consent undergoing cardiac surgery from June to September in 2012 were enrolled. At least one structured interview was performed postoperatively with the modified Brice Interview Questionnaire to identify intraoperative awareness as confirmed awareness, possible awareness, and no awareness. Confirmed awareness events reported by patients were classified into different categories with the Michigan Awareness Classification Instrument. The questionnaire results were combined with the patient medical records. A logistic regression model was used to analyze the risk factors that may have led to intraoperative awareness.

Results: An estimated 2136 patients were included, and 1874 patients completed at least one interview. 83 patients (4.4\%) were identified as possible or confirmed awareness, among which 46 (2.5\%) reported confirmed awareness. Patients who experienced confirmed awareness were mostly of Class 1 and 2, 15 and 24 patients respectively, which represented isolated auditory and tactile perceptions. And 11 patients reported feelings of distress intraoperatively. Hyperlipidemia was associated with intraoperative awareness $(\mathrm{OR}=0.499,95 \% \mathrm{Cl}=0.252-$ $0.989, p=0.043$ ) and using chi-square test, however, no significance was found with logistic regression.

Conclusion: Patients undergoing cardiac surgery are at high risk for intraoperative awareness. Distress is a common feeling in patients with intraoperative awareness. Hyperlipidemia is a potential protective factor for intraoperative awareness in cardiac surgery.

Keywords: Anesthesia, Cardiac surgery, Hyperlipidemia, Intraoperative complications, Intraoperative awareness, Protective factor

\section{Background}

Intraoperative awareness is defined as "...the postoperative recollection of events occurring during general anesthesia", [1] which is an infrequent but dreaded complication that occurs in patients undergoing general anesthesia at an incidence of $0.10-1.05 \%$ among non-

\footnotetext{
* Correspondence: wangzf211@sina.com; aohushan@126.com

First co-authors are Qingshui Zheng and Qian Wang.

${ }^{2}$ Department of Anesthesiology, Ordos Central Hospital, Inner Mongolia

Medical University, Inner Mongolia, China

${ }^{3}$ Fuwai Hospital, Peking Union Medical College, Chinese Academy of Medical Sciences, Beijing, China

Full list of author information is available at the end of the article
}

cardiac surgery reports (Table 1 ). It is relatively more frequent in cardiac surgery: reported as $6 \%$ in China in 2009 by Xu et al. [2] and an unexpectedly high incidence of $23 \%$ by Goldman et al. [3] in 1987. We found a rate of $3.0 \%$ in 2013 [4]. Though Awareness with explicit recall is not a lethal complication, psychologically adverse symptoms, such as post-traumatic stress disorder (PTSD) characterized by 're-experiencing, avoidance, and physiological hyperarousal' [5] may develop, commonly and persistently, in the patients who experience anesthesia awareness [6]. Identification of risk factors contributing to awareness deserves further study, and 
Table 1 Incidence of intraoperative awareness in reported studies

\begin{tabular}{llll}
\hline Author & Country & Year & Incidence (\%) \\
\hline NON-CARDIAC SURGERY & & & \\
Myles, et al. [9] & Australia & 2000 & 0.10 \\
Akavipat, et al. [10] & Thailand & 2009 & 1.05 \\
Sebel, et al. [11] & U.S.A. & 2004 & 0.13 \\
Sandin, et al. [12] & Sweden & 2000 & 0.16 \\
Xu, et al. [2] & China & 2009 & 0.41 \\
CARDIAC SURGERY & & & \\
Maunuksela [16] & - & 1977 & 5.0 \\
Goldmann, et al. [3] & - & 1987 & 23 \\
Gordon, et al. [15] & South Africa & 1994 & 1.1 \\
Wang Yun, et al. [17] & China & 2005 & 6 \\
Xu, et al. [2] & China & 2009 & 6 \\
Qian Wang, et al. [4] & China & 2013 & 3.0 \\
\hline
\end{tabular}

corresponding strategies to prevent awareness during general anesthesia are justified.

\section{Methods}

\section{Patient population}

The study was approved by the Institutional Review Board of Fuwai Hospital in Beijing, China. Patients with Written informed consents receiving selective cardiac surgery under general anesthesia from June to September in 2012 were enrolled. Inclusion criteria were patients older than 18 years, with normal mental status, and able to provide informed consent. Patients were excluded if they did not meet the criteria or were not able to complete the follow-up questionnaires: (1) died intra- or postoperatively in the hospital; (2) could not be extubated early within 3-6 days; (3) could not communicate readily; (4) had abnormal mental status.

A sample of 1525 patients was estimated initially based on our prior study [4] that found a rate of intraoperative awareness of $3.0 \%$. We took a possible loss-to-follow-up rate of $30 \%$ into consideration and set the final sample target at 2136 patients.

\section{Conduct of the study}

Individual practitioners, who were blinded to the study, made anesthetic algorithms, including anesthetic drugs and depth of anesthesia monitoring case-by-case. All patients were transferred to the Intensive Care Unit (ICU) for a period of postoperative sedation and ventilation, and then transferred to wards where the patients were awakened and extubated.

Each patient was interviewed by research staff with the modified Brice Interview [7]. The research staff classified each patient report into confirmed awareness, possible awareness, and no awareness on the basis of published definitions [8]. Events were classified according to the Michigan Awareness Classification Instrument [8].
Patients who reported awareness received follow-up interviews to determine if the events confirmed awareness. The occurrence of awareness during the ICU stay would be excluded.

\section{Statistical analysis}

The patient medical records were retrieved and combined with postoperative questionnaire results. Descriptive statistics were used to describe the incidence of intraoperative awareness of cardiac surgery. Comparisons of continuous variables between the "Confirmed Awareness" and "No Awareness or Possible Awareness" groups were conducted with the independent sample $t$ test, and categorical variables between groups with Fisher's exact test or chi-square test, with or without Yates' continuity correction. $P$ values of less than or equal to 0.05 were considered to indicate statistical significance. The statistical analyzes were performed with SPSS 21.0 (SPSS Inc., Chicago, IL).

\section{Results}

Patients

Figure 1 shows the selection of patients included. Of all the estimated 2136 patients, 230 were excluded because of rejection to or being not competent for informed consent, surgery cancelation, or preexisting hearing loss. One thousand nine hundred six patients entered the study during a 4-month period from June to September in 2012, and a total of 1874 patients completed the study. Thirty-two patients were excluded because they were lost to follow-up after surgery due to death (10 cases), insufficient or missing data (11 cases), being not competent for a structured interview, and other reasons (11 cases).

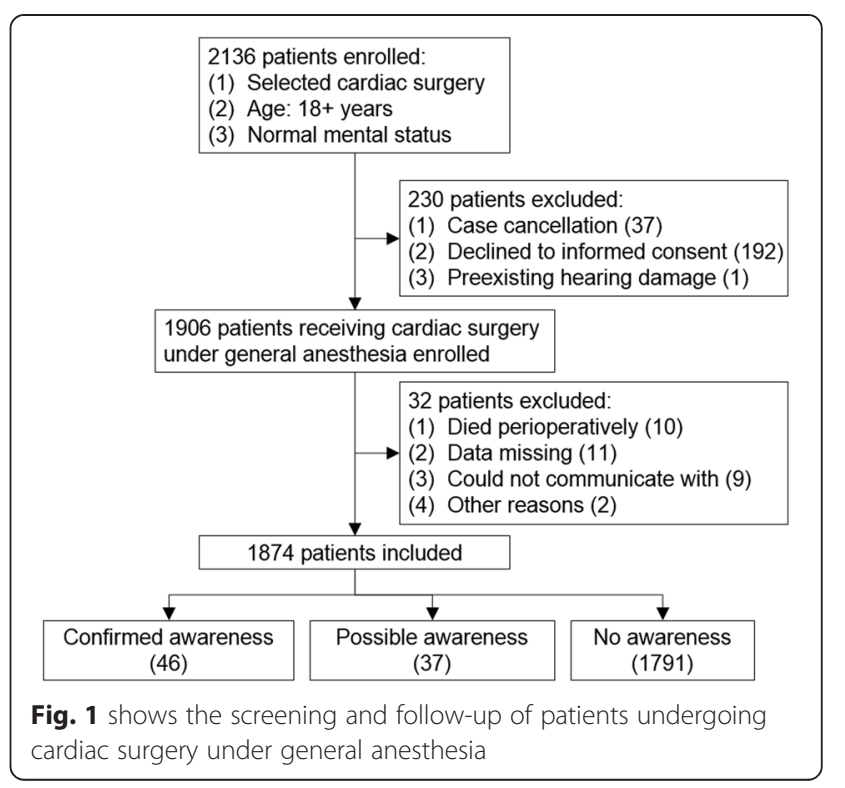




\section{Occurrence of intraoperative awareness}

Among the 1874 patients interviewed, 46 (2.5\%) were identified as confirmed awareness, 37 (1.9\%) as possible awareness, and 1791 (95.6 \%) as no awareness. Detailed descriptions of recollections are listed in Table 2. Each patient who experienced confirmed awareness reported at least one event during general anesthesia. Figure 2 shows the timing of reported awareness events. Six-teen of the patients reported events that occurred during the period between anesthesia induction and skin incision, most of which were perceptions of intubation and central line placement; 18 reported events during surgery, not all known the exact timing of the surgery due to lack of exact markers of specific events; five reports were identified at the very end of the surgery; and 24 patients reported sounds, pains and perceptions but were not able to determine when they occurred.

Reports of confirmed awareness were classified into six levels, from Class 0 to 5 , and an additional D for "distress" was included, according to the Michigan Awareness Classification Instrument (Fig. 3).

\section{Risk factors for intraoperative awareness}

Table 3 shows the demographic characteristics of patients with confirmed awareness, compared with patients who had no awareness or possible awareness. Patients who reported confirmed awareness had a lower rate of hyperlipidemia ( $23.9 \%$ vs. $38.6 \%, p=0.043$, OR $=0.499$, $95 \% \mathrm{CI}=0.252-0.989)$ and had a shorter duration of surgery $(195.0 \pm 52.0 \mathrm{~min}$ vs. $225.2 \pm 82.4 \mathrm{~min}, p=$ 0.013), compared with the other patients. And patients who were young than 60 years old age showed a higher rate of awareness than those who were elder than 60 $(1.9 \%$ vs. $0.5 \%, p=0.026)$. No differences were seen in other pre- and intraoperative factors. And no significance was found between hyperlipidemia and awareness when age, hyperlipidemia and duration of operation were entered into logistic regression. $(p=0.159, \mathrm{OR}=$ 0.604, $95 \% \mathrm{CI}=0.300-1.218$ ) (Table 4).

\section{Discussion}

\section{Incidence}

In the present study, we found the awareness rate in cardiac surgery was $2.5 \%$, which was considerably higher than that in general surgery [2, 9-12]. Several factors may have contributed to the higher occurrence of anesthesia awareness. Patients are particularly vulnerable to awareness during painful procedures such as sternotomy, electrocauterization, or any surgical manipulations and strong stimulations like endotracheal intubation [3]. Publications what address risk factors for more frequent awareness in cardiac procedures also mention compromised hemodynamics, insufficient anesthesia or analgesia that may have resulted from underdosing of anesthetic agents related to a patient's specific requirements [13], and alterations in pharmacokinetics or pharmacodynamics of drugs during cardiopulmonary bypass [14].

The awareness rate in this investigation differed notably from other studies in cardiac surgery [2-4, 15-17]. The differences might be explained by methodology [18], human factors [18], and race; other factors that may have influenced the assessed awareness rate were the definition of awareness. Study methodology, including the number of patient interviews and especially the time elapsed after surgery when the patients were interviewed, and characteristics of the patients, as well as the number of patients evaluated. Another factor that likely influences inter-study comparability are the differences in routine practice between hospitals and between anesthesiologists, which is difficult to control in an analysis. Also, the ethnic difference may partially lead to the different results. Non-Chinese patients were enrolled in most of the prior studies, whereas all the patients in the present study were Ethnic Chinese. An ethnic difference has been reported in certain fields, like blood coagulation function and the fibrinolysis system [19, 20], along with differences in responses to special drugs, such as warfarin [21, 22].

\section{Distribution of the timing of intraoperative awareness}

In this study, 16 patients reported events that occurred after anesthesia induction, but prior to the skin incision, of which mostly are endotracheal intubation and central line placement. Although analgesics like fentanyl will blunt hemodynamic responses to intubation to some degree, attempting to attenuate arousal of cerebral cortical activity has failed [23]. When a difficult airway is presented, multiple strong stimulations of intubation attempting might contribute to more frequent occurrences of explicit recall. Meanwhile, the depth of anesthesia will lower down once the maintenance of anesthesia is not scheduled during the attempting. During operation 18 patients experienced awareness, not being able to recognize the exact timing of the events. Only few events were well identified by specific time or manipulations, especially auditory perceptions and general manipulations that might occur throughout surgery. Five complaints occurred at the end of the surgery, which was when the depth of anesthesia was lowest to adapt to the reduced stimuli and avoid further compromising hemodynamics.

\section{Michigan Awareness Classification}

Confirmed awareness graded by the Michigan Awareness Classification is shown in Fig. 3. While the majority of awareness events in Classes 1 and 2 were related to auditory and tactile perceptions ( 39 of the 46 confirmed 
Table 2 Descriptions of confirmed awareness reported by patients

\begin{tabular}{|c|c|c|c|c|}
\hline Number & $\begin{array}{l}\text { Gender } \\
\text { and age }\end{array}$ & Surgery & Reported events & $\begin{array}{l}\text { Michigan awareness } \\
\text { classification }\end{array}$ \\
\hline 1 & $M / 67$ & CABG & Formication; perception of central line placement; mild pain & Class 3 \\
\hline 2 & $M / 73$ & Bentall procedure & Precordial stabs; nausea & Class 2D \\
\hline 3 & $M / 64$ & CABG & Operation on the chest & Class 2 \\
\hline 4 & $\mathrm{M} / 30$ & $\begin{array}{l}\text { Repair of aneurysm of aortic } \\
\text { sinus, repair of VSD }\end{array}$ & Perception of central line placement & Class 2 \\
\hline 5 & $F / 53$ & MVR & Placement of nasal thermometer & Class 2 \\
\hline 6 & $M / 23$ & Modified Morrow procedure & A surgeon making explanations in a Tangshan accent & Class 1 \\
\hline 7 & M/65 & Wheat procedure and CABG & Dreaming things back in decades ago; lower extremity operation & Class 2 \\
\hline 8 & M/66 & CABG & Intubation & Class 2 \\
\hline 9 & $\mathrm{M} / 40$ & $\begin{array}{l}\text { Repair of aneurysm of } \\
\text { aortic sinus }\end{array}$ & Intubation; operation, electroshock on heart & Class 2 \\
\hline 10 & M/67 & CABG & Intubation, feeling nausea twice & Class 2D \\
\hline 11 & $M / 60$ & CABG & Scalpel incision; voice from doctors & Class 2 \\
\hline 12 & $M / 60$ & CABG & Intubation; internal jugular vein catheterization & Class 2 \\
\hline 13 & M/65 & CABG & Sensation of operation on chest and lower limb & Class 2 \\
\hline 14 & M/66 & Resection of atrial myxoma, TVP & Feelings of bugs-like crawling on the chest & Class 2 \\
\hline 15 & $\mathrm{M} / 38$ & ASD repair, TVP & Sensation of sounds from the respirator & Class 1 \\
\hline 16 & $M / 56$ & CABG & Heard the surgeons' talking & Class 1 \\
\hline 17 & $F / 45$ & MVR, TVP & Heard the sounds of electric scalpel, like "chi, chi" & Class 1 \\
\hline 18 & $F / 18$ & ASD repair & Intubation; nausea; discomfort on the back & Class 2D \\
\hline 19 & $F / 59$ & MVR, TVP & Operation & Class 2 \\
\hline 20 & M/49 & CABG & $\begin{array}{l}\text { Water dripping-like sounds of the machine; sensation of intubation } \\
\text { and a severe feeling of nausea }\end{array}$ & Class 2D \\
\hline 21 & $\mathrm{~F} / 56$ & CABG & Sensation of the operation; severe pain, being unable to move & Class 5 \\
\hline 22 & $M / 55$ & $\begin{array}{l}\text { Correction of aberrant of } \\
\text { pulmonary artery, TVP }\end{array}$ & Sounds of the machine in the operation room & Class 1 \\
\hline 23 & $M / 34$ & $\begin{array}{l}\text { Replacement of aortic root and } \\
\text { ascending aorta }\end{array}$ & Sounds of a scalpel and scissor & Class 1 \\
\hline 24 & $F / 51$ & Replacement of ascending aorta & $\begin{array}{l}\text { Heard the surgeon talking about the electric defibrillations, of which } \\
\text { only the third time worked }\end{array}$ & Class 1 \\
\hline 25 & $\mathrm{~F} / 60$ & MVR, AVR, TVP & $\begin{array}{l}\text { Heard the surgeon said the operation was well finished; intubation; } \\
\text { felt nausea twice }\end{array}$ & Class 2D \\
\hline 26 & $\mathrm{~F} / 50$ & MVP & $\begin{array}{l}\text { Dreaming, cannot afford details; heard the surgeon's talking; central } \\
\text { line placement }\end{array}$ & Class 2 \\
\hline 27 & $M / 58$ & CABG & Lower limb operation & Class 2 \\
\hline 28 & $M / 74$ & CABG & Intubation; felt nausea; sensation of the operation on the chest & Class 2D \\
\hline 29 & $M / 62$ & CABG & Operation on chest with burning heat & Class 2 \\
\hline 30 & $\mathrm{~F} / 30$ & Repair of ASD, TVP & Sounds like sawing wood & Class 1 \\
\hline 31 & $F / 31$ & Repair of ASD, TVP & Voice, such as "pass the scalpel to me" & Class 1 \\
\hline 32 & $M / 43$ & Modified Morrow procedure & Operation on chest; severe pain, wanting for more anesthetics & Class 3D \\
\hline 33 & $M / 60$ & CABG & Felt awake for a long time and felt like breathing with effort & Class 1D \\
\hline 34 & $M / 52$ & Bentall procedure & Heard "chi-chi" like sounds & Class 1 \\
\hline 35 & $M / 46$ & MVR, AVR, TVP & $\begin{array}{l}\text { Heard the surgeon said the operation will be finished in an hour; } \\
\text { heard the "dong-dong" like sounds }\end{array}$ & Class 1 \\
\hline 36 & $M / 37$ & MVR & $\begin{array}{l}\text { Dreaming of receiving cardiac surgery; sensed the central line } \\
\text { placement }\end{array}$ & Class 2 \\
\hline 37 & $F / 48$ & MVR, TVP, and PDA repair & Scissors cutting on the chest; mild pain & Class 3 \\
\hline
\end{tabular}


Table 2 Descriptions of confirmed awareness reported by patients (Continued)

\begin{tabular}{|c|c|c|c|c|}
\hline 38 & $M / 60$ & CABG & Operation on chest and lower limb & Class 2 \\
\hline 39 & $M / 41$ & CABG & $\begin{array}{l}\text { Something dragged down from the chest; unable to move; central } \\
\text { line placement }\end{array}$ & Class 4 \\
\hline 40 & $M / 59$ & MVR, CABG & "chi-chi" sound & Class 1 \\
\hline 41 & $M / 34$ & CABG & $\begin{array}{l}\text { Dreaming of the lifetime in high school; heard the surgeon said the } \\
\text { operation was almost finished }\end{array}$ & Class 1 \\
\hline 42 & $F / 58$ & CABG & $\begin{array}{l}\text { Heard the surgeon said } 5 \text { bypass grafts were done, and the } 2 \\
\text { nurses had done a great job }\end{array}$ & Class 1 \\
\hline 43 & $\mathrm{M} / 40$ & AVR & Intubation; unable to move; afraid & Class 4D \\
\hline 44 & $M / 57$ & CABG & Chest stuffy, unable to speak & Class 4D \\
\hline 45 & $M / 56$ & $\begin{array}{l}\text { Replacement of descending } \\
\text { aorta }\end{array}$ & Intubation; nausea & Class 2D \\
\hline 46 & $M / 54$ & CABG & $\begin{array}{l}\text { Heard the surgeon said the operation was well done; felt his chest } \\
\text { stabbed } 4-5 \text { times. }\end{array}$ & Class 2 \\
\hline
\end{tabular}

Abbreviations: CABG coronary artery bypass grafting, MVR mitral valve replacement, $A V R$ aortic valve replacement, $T V P$ tricuspid valvuloplasty, $P D A$ patent ductusarteriosus

awareness events), only seven cases with mild-to-severe pain, with or without a sensation of paralysis, were classified as Grade 3 to 5 . Meanwhile, 11 patients (24\%) experienced distress from fear, nausea and being unable to speak. In a previous prospective randomized trial, five out of nine patients had confirmed awareness of Class 1 and 2, and five out of nine cases experienced distress [24]. These finding demonstrated that patients were more likely to experience a lower class of intraoperative awareness. However, distress during the period of awareness was frequently found. Therefore, careful postoperative follow-up should be arranged for patients complaining of awareness.

\section{Hyperlipidemia and awareness}

As shown in Table 3, patients who reported confirmed awareness had a shorter duration of surgery (195.0 \pm $52.0 \mathrm{~min}$ vs. $225.2 \pm 82.4 \mathrm{~min}, p=0.013$, OR $=0.994,95 \%$ $\mathrm{CI}=0.990-0999)$, compared with the other patients. However, as the odds ratio is proximal to the value 1 , duration

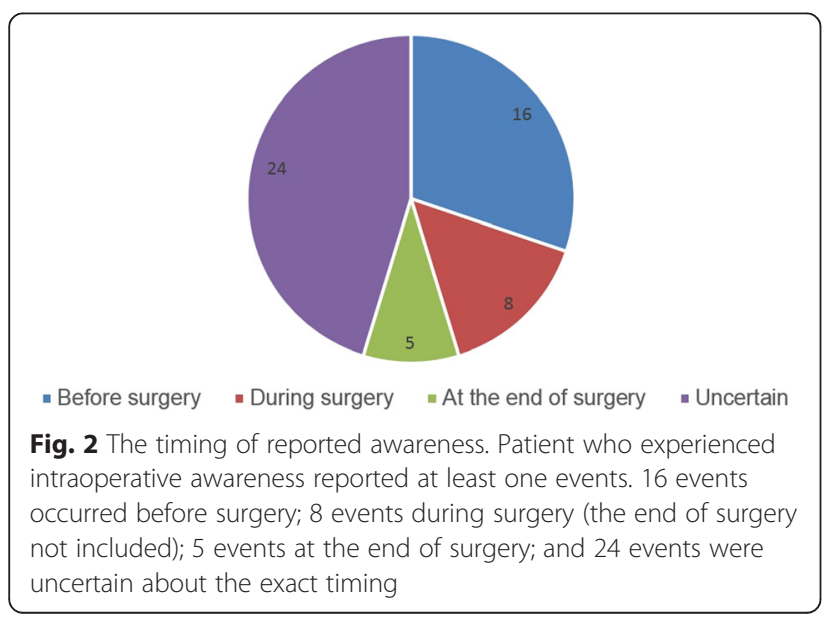

of operation won't be considered as a significant index for establishing a risk factor for the patients' intraoperative awareness.

Interestingly, this study indicated that hyperlipidemia was negatively related to anesthesia awareness using chisquare tests, demonstrating that hyperlipidemia is a potential protective factor against intraoperative awareness in cardiac surgery. As the elder people suffer hyperlipidemia more frequently, to clarify that hyperlipidemia is an independent protective factor rather than a coincidence with old age, a logistic regression where age, duration of operation and hyperlipidemia were entered into

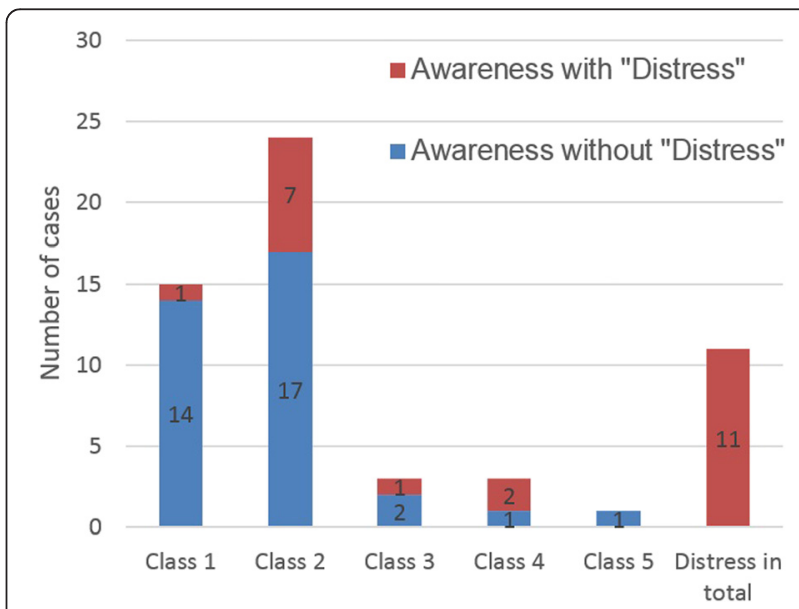

Fig. 3 The Michigan Awareness Classification of Awareness. Class 1 denotes isolated auditory perceptions; Class 2 tactile perceptions (e.g., surgical manipulation or endotracheal tube); Class 3 pain; Class 4 paralysis (e.g., feeling one cannot move, speak or breathe); Class 5 paralysis and pain. "Distress" was assessed when a patient reported of fear, anxiety, suffocation, sense of doom, sense of impending death, etc. The red column indicates the patients with distress, and blue column indicates the patients without distress 
Table 3 Demographic characteristics of study population $(n=1874)$

\begin{tabular}{|c|c|c|c|}
\hline Characteristic & No awareness or possible awareness & Confirmed awareness & $P$ Value \\
\hline Age-no. (\%) & - & - & $0.026^{*}$ \\
\hline$<60$ year old & $1137(60.7)$ & $36(1.9)$ & - \\
\hline$>60$ year old & $691(36.9)$ & $10(0.5)$ & - \\
\hline Male-no. (\%) & $1212(66.3)$ & $33(73.9)$ & 0.28 \\
\hline Height-cm & $165.7 \pm 8.7$ & $166.1 \pm 8.1$ & 0.80 \\
\hline Weight-kg & $68.0 \pm 12.4$ & $67.7 \pm 12.9$ & 0.88 \\
\hline BMI & $24.8 \pm 6.5$ & $24.4 \pm 3.7$ & 0.67 \\
\hline Blood group-no. (\%) & - & - & 0.34 \\
\hline A & $511(28.1)$ & $16(34.8)$ & - \\
\hline B & $607(33.4)$ & $18(39.1)$ & - \\
\hline$A B$ & $188(10.4)$ & $2(4.3)$ & - \\
\hline $\mathrm{O}$ & $510(28.4)$ & $10(21.7)$ & - \\
\hline Existing risk factors-no. (\%) & - & - & - \\
\hline Smoking & $824(45.1)$ & $21(47.8)$ & 0.72 \\
\hline Alcohol consumption & $236(12.9)$ & $5(10.9)$ & 0.68 \\
\hline Hypertension & $860(47.1)$ & $15(32.6)$ & 0.052 \\
\hline Hyperlipidemia & $705(38.6)$ & $11(23.9)$ & $0.043^{*}$ \\
\hline Diabetes mellitus & $342(18.7)$ & $6(13.0)$ & 0.33 \\
\hline Chronic kidney disease & $13(0.7)$ & $1(2.2)$ & 0.30 \\
\hline Chronic liver disease & $21(1.2)$ & $0(0)$ & 1.00 \\
\hline Cerebrovascular events & $39(2.1)$ & $1(2.2)$ & 1.00 \\
\hline Chronic obstructive pulmonary disease & $43(2.4)$ & $0(0)$ & 0.62 \\
\hline History of general anesthesia & $411(22.5)$ & $6(13.0)$ & 0.13 \\
\hline History of cardiac infarction & $320(17.5)$ & $7(15.2)$ & 0.68 \\
\hline ASA status-no. / total no. (\%) & - & - & 0.48 \\
\hline I & $11(0.61)$ & $1(2.2)$ & - \\
\hline$\|$ & $533(29.5)$ & $16(34.8)$ & - \\
\hline III & $1167(64.5)$ & $27(58.7)$ & - \\
\hline IV & $97(5.4)$ & $2(4.3)$ & - \\
\hline NYHA grade & - & - & 0.53 \\
\hline Lower than Grade 1 & $510(27.9)$ & $9(20.0)$ & - \\
\hline Grade 1 & $177(9.7)$ & $7(15.2)$ & - \\
\hline Grade 2 & $779(42.7)$ & $21(45.7)$ & - \\
\hline Grade 3 & $340(18.6)$ & $9(20.0)$ & - \\
\hline Grade 4 & $20(1.1)$ & $0(0)$ & - \\
\hline Ejection fraction (\%) & $61.2 \pm 8.7$ & $62.3 \pm 7.6$ & 0.40 \\
\hline Duration of surgery-min & $225.2 \pm 82.4$ & $195.0 \pm 52.0$ & $0.013^{*}$ \\
\hline Cardiopulmonary Bypass-no. (\%) & $1321(72.3)$ & $30(68.2)$ & 0.95 \\
\hline Duration of CPB-min & $106.2 \pm 47.4$ & $91.2 \pm 40.0$ & 0.071 \\
\hline Aortic clamping time-min & $71.7 \pm 32.1$ & $62.6 \pm 33.3$ & 0.11 \\
\hline
\end{tabular}

Plusminus values are means $\pm S D$

Abbreviations: BMI denotes body-mass index, ASA denotes American Society of Anesthesiologists, NYHA grade denotes New York Heart Association grade, CPB is cardiopulmonary bypass 
Table 4 Logistic regression analysis of risk factors for confirmed awareness

\begin{tabular}{|c|c|c|c|c|c|c|c|c|}
\hline & \multirow[t]{2}{*}{ B } & \multirow[t]{2}{*}{ S.E. } & \multirow[t]{2}{*}{ Wald } & \multirow[t]{2}{*}{$d f$} & \multirow[t]{2}{*}{$P$ value } & \multirow[t]{2}{*}{ OR } & \multicolumn{2}{|c|}{$95 \% \mathrm{Cl}$ for OR } \\
\hline & & & & & & & Lower & Upper \\
\hline Hyperlipidemia & -0.504 & 0.358 & 1.984 & 1 & 0.159 & 0.604 & 0.300 & 1.218 \\
\hline Age & -0.623 & 0.369 & 2.854 & 1 & 0.091 & 0.536 & 0.260 & 1.105 \\
\hline Duration of Operation & -0.006 & 0.002 & 5.593 & 1 & 0.018 & 0.094 & 0.990 & 0.999 \\
\hline Constant & -1.650 & 0.623 & 7.006 & 1 & 0.008 & 0.192 & - & \\
\hline
\end{tabular}

Abbreviations: $O R$ denotes odds ratio, $\mathrm{Cl}$ confidence interval

was done and found no association between hyperlipidemia and awareness.

However, an animal experiment conducted in mice revealed that high cholesterol level increases the antinociceptive effect of opioids and an analysis of the clinical records in the China-Japan Friendship Hospital (Beijing, China) was carried out to conclude that there exists a reverse correlation between the serum cholesterol and opioid efficacy in human [25]. As patients are subjected to awareness more often during painful procedures such as sternotomy and strong stimulations such as endotracheal intubation [3], the enhanced analgesia effect of opioids in the patients with hyperlipidemia like hypercholesterolemia will lower down the occurrence of anesthesia awareness. Nevertheless, a prospective cohort study is needed to reveal the relationship between hyperlipidemia and awareness. The coming era of translational medicine promises to clarify whether genetic variations contribute to a possibly lower risk of intraoperative awareness among patients with hyperlipidemia.

\section{Limitations}

One of the limitations would be the timing for interviews. Since it is difficult to determine when patients will regain consciousness and as a result of the disability to communicate while still remain intubated for compromised hemodynamics, it is tough for the researchers to initiate the first interview at the appropriate time. Similarly, the patients would be discharged after surgery in 1 to 2 weeks, making it relative limited time for research staff to conduct the follow-up questionnaires. Since patients mostly report intraoperative awareness within 30 days, the true incidence of awareness may have been higher.

Another consideration is that the lack of appropriate hallmarks for identifying the specific timing of each reported events had complicated the analysis of the risk factors.

\section{Conclusions}

Patients undergoing cardiac surgery are at relatively higher risk for intraoperative awareness. Distress during awareness as an outstanding discomfort during the surgery with implications for postoperative psychological complications in the hospital and long-term outcomes following the awareness, deserves the attention of anesthesiologists. Hyperlipidemia is a potential protective factor for intraoperative awareness for patients receiving cardiac surgery.

\section{Competing interests}

The authors declare that they have no competing interests.

\section{Authors' contributions}

QZ: Study design, patient recruitment, and data collection and writing up the first draft; QW: Study design, patient recruitment, and data collection; CW: Data analysis, data interpretation; ZW: Critical revision, final approval of publication; HA: Study conception and design, critical revision, final approval of publication. All authors read and approved the final manuscript.

\section{Acknowledgements}

We would like to express our great appreciation to Pro. Hushan Ao and Pro. Zhifa Wang for their valuable and constructive suggestions during the planning and development of this research work. And our grateful thanks are also extended to the staffs of the Department of the SICU, for their support of our work. We also would like to express special thanks to Dr. Lei $\mathrm{Li}$, and Mr. Sipeng Chen for their critical suggestions on data collection and data analysis.

\section{Author details}

'Department of Anesthesiology, Fuwai Hospital, Peking Union Medical College, Chinese Academy of Medical Sciences, Beijing, China. ${ }^{2}$ Department of Anesthesiology, Ordos Central Hospital, Inner Mongolia Medical University, Inner Mongolia, China. ${ }^{3}$ Fuwai Hospital, Peking Union Medical College,

Chinese Academy of Medical Sciences, Beijing, China.

Received: 9 September 2015 Accepted: 5 April 2016

Published online: 12 April 2016

\section{References}

1. Myles PS, Leslie K, McNeil J, Forbes A, Chan MT. Bispectral index monitoring to prevent awareness during anaesthesia: the B-aware randomised controlled trial. Lancet. 2004:363:1757-63.

2. $\mathrm{Xu} L$, Wu AS, Yue $Y$. The incidence of intra-operative awareness during general anesthesia in china: a multi-center observational study. Acta Anaesthesiol Scand. 2009;53:873-82.

3. Goldmann L, Shah MV, Hebden MW. Memory of cardiac anaesthesia. Psychological sequelae in cardiac patients of intra-operative suggestion and operating room conversation. Anaesthesia. 1987:42:596-603.

4. Wang Q, Wang Z, Hao Z, Ao H. The occurrence of intraoperative awareness in cardiac surgery Chinese. J Anesth. 2013;33:1407-8.

5. Runeson BS, Rich CL. Diagnostic and statistical manual of mental disorders, 3rd ed. (DSM-III), adaptive functioning in young Swedish suicides. Ann Clin Psychiatry. 1994:6:181-3.

6. Leslie K, Chan MT, Myles PS, Forbes A, McCulloch TJ. Posttraumatic stress disorder in aware patients from the B-aware trial. Anesth Analg. 2010; 110:823-8.

7. Brice DD, Hetherington RR, Utting JE. A simple study of awareness and dreaming during anaesthesia. Br J Anaesth. 1970;42:535-42.

8. Mashour GA, Tremper KK, Avidan MS. Protocol for the "Michigan awareness control study": a prospective, randomized, controlled trial comparing 
electronic alerts based on bispectral index monitoring or minimum alveolar concentration for the prevention of intraoperative awareness. BMC Anesthesiol. 2009;9:7.

9. Myles PS, Williams DL, Hendrata M, Anderson H, Weeks AM. Patient satisfaction after anaesthesia and surgery: results of a prospective survey of 10,811 patients. Br J Anaesth. 2000;84:6-10.

10. Akavipat $P$, Sookplung $P$, Premsamran $P$, Toomtong P, Kusumaphanyo $C$, Muansaiyart $P$. The Thai anesthesia incident monitoring study (Thai AIMS): an analysis of 21 awareness events. J Med Assoc Thai. 2009;92:335-41.

11. Sebel PS, Bowdle TA, Ghoneim MM, Rampil IJ, Padilla RE, Gan TJ, Domino $\mathrm{KB}$. The incidence of awareness during anesthesia: a multicenter united states study. Anesth Analg. 2004;99:833-9. table of contents.

12. Sandin RH, Enlund G, Samuelsson P, Lennmarken C. Awareness during anaesthesia: a prospective case study. Lancet. 2000;355:707-11.

13. Ghoneim MM, Block Rl, Haffarnan M, Mathews MJ. Awareness during anesthesia: risk factors, causes and sequelae: a review of reported cases in the literature. Anesth Analg. 2009;108:527-35.

14. Tempe DK, Siddiquie RA. Awareness during cardiac surgery. J Cardiothorac Vasc Anesth. 1999;13:214-9.

15. Gordon PC, Morrell DF, Pamm JD. Total intravenous anesthesia using propofol and alfentanil for coronary artery bypass surgery. J Cardiothorac Vasc Anesth. 1994:8:284-8.

16. Maunuksela EL. Hemodynamic response to different anesthetics during open-heart surgery. Acta Anaesthesiol Scand Suppl. 1977;65:1-71.

17. Wang Y, Yue Y, Sun YH, Wu AS, Wu QW, Zhang YQ, Feng CS. Investigation and analysis of incidence of awareness in patients undergoing cardiac surgery in Beijing, china. Chin Med J (Engl). 2005;118:1190-4.

18. Errando CL, Perez-Caballero P, Gelb AW, Sigl JC. Methodology, human factors, and incidence of intraoperative awareness. Acta Anaesthesiol Scand. 2010:54:781-3.

19. Kain K, Catto AJ, Grant PJ. Impaired fibrinolysis and increased fibrinogen levels in south Asian subjects. Atherosclerosis. 2001;156:457-61.

20. Forouhi NG, Rumley A, Lowe GD, McKeigue P, Sattar N. Specific elevation in plasma tissue plasminogen activator antigen concentrations in south Asians relative to Europeans. Blood Coagul Fibrinolysis. 2003:14:755-60.

21. Yu HY, Liu CH, Chen YS, Wang SS, Chu SH, Lin FY. Relationship of international normalized ratio to bleeding and thromboembolism rates in Taiwanese patients receiving vitamin $\mathrm{K}$ antagonist after mechanical valve replacement. J Formos Med Assoc. 2005;104:236-43.

22. McEvoy MD, Reeves ST, Reves JG, Spinale FG. Aprotinin in cardiac surgery: a review of conventional and novel mechanisms of action. Anesth Analg. 2007;105:949-62.

23. Mi WD, Sakai T, Takahashi S, Matsuki A. Haemodynamic and electroencephalograph responses to intubation during induction with propofol or propofol/fentanyl. Can J Anaesth. 1998;45:19-22.

24. Avidan MS, Jacobsohn E, Glick D, Burnside BA, Zhang L, Villafranca A, Karl L, Kamal S, Torres B, O'Connor M, Evers AS, Gradwohl S, Lin N, Palanca BJ, Mashour GA, Group B-RR. Prevention of intraoperative awareness in a highrisk surgical population. N Engl J Med. 2011;365:591-600.

25. Zheng H, Zou H, Liu X, Chu J, Zhou Y, Loh HH, Law PY. Cholesterol level influences opioid signaling in cell models and analgesia in mice and humans. J Lipid Res. 2012;53:1153-62.

\section{Submit your next manuscript to BioMed Central and we will help you at every step:}

- We accept pre-submission inquiries

- Our selector tool helps you to find the most relevant journal

- We provide round the clock customer support

- Convenient online submission

- Thorough peer review

- Inclusion in PubMed and all major indexing services

- Maximum visibility for your research

Submit your manuscript at www.biomedcentral.com/submit

Biomed Central 